УДК 316

$10.17213 / 2075-2067-2020-5-21-32$

\title{
МИГРАЦИОННЫЕ ПОТОКИ РОСТОВСКОЙ ОБЛАСТИ В УСЛОВИЯХ ПАНДЕМИИ СOVID-19
}

\author{
(C) 2020 г. Н. Г. Волков, И. В. Печкуров, В. Г. Пантелеев \\ Южно-Российский филиал Федерального научно-исследовательского \\ социологического центра РАН, г. Ростов-на-Дону, Россия
}

Целью исследования является выявление особенностей поведения миграционных потоков Ростовской области - внутрирегионального, межрегионального и международного - в условиях ограничения перемещений людей в связи с пандемией COVID-19. В частности, выявляется, насколько миграционные потоки могут восстанавливаться после ослабления ограничения перемещеений, то есть их устойчивость.

Методологическую основу исследования составляет, во-первых, наблюдение за изменением статистических рядов, которые характеризуют динамику внутрирегионального, межрегионального и международного миграџионных потоков Ростовской области; во-вторых, компаративистика статистических рядов в разные временные отрезки (годовые и месячные), позволяющая выявить относительную норму объемов миграчионных потоков и отклонение от нормы в период действия ограничения перемещений людей; в-третьих, фиксирование в наблюдении изменений статистических рядов под воздействием фактора и таким образом определение, оказывает ли фактор влияние на динамику статистического ряда или не оказывает.

Результаты исследования. Во-первых, выявлено, что внутрирегиональный миграционный поток демонстрирует большую чувствительность к влиянию фактора ограничения перемещений людей, объем его снизился; тем не менее, он проявил высокую степень возобновляемости после ослабления ограничений. На миграџионном приросте региона это никак не сказалось в силу особенностей внутрирегиональных перемещзений. Во-вторых, выявлено, что межрегиональный миграчионный поток также чувствителен к влиянию фактора ограничения перемещений людей и в то же время продемонстрировал высокую степень возобновляемости после ослабления ограничений; также в условиях пандемии снижение интенсивности этого мигращиионного потока уменьшило отток жителей Ростовской области в другие регионы. В-третьих, выявлено, что международный миграционный поток продемонстрировал те же самые свойства по части прибывающих в область, но эти свойства никак не проявились по части уезжающих из региона за рубеж; на уменьшение прироста за счет международных мигрантов фактор ограничений повлиял слабо. Таким образом, миграционные потоки Ростовской области испытали реальное влияние ограничительных мер и в то же время продемонстрировали свою устойчивость и возобновляемость после ослабления ограничивающего перемещения фактора.

Перспективу исследования составляет дальнейшее научное наблюдение за изменениями миграчионных потоков на региональном уровне и влияние на них фактора ограничения перемещеений людей в связи пандемией COVID-19. Так как окончание пандемии плохо прогнозируемо, то, вероятно, ограничиваюшие меры будут вводиться не один раз, в связи с чем важно иметь результаты наблюдений за поведением миграционных потоков в первый период ограничений, затем во второй, третий и так далее с тем, чтобы выявить долгосрочный эффект влияния ограничивающих мер на поведение мигращионных потоков на региональном уровне. 
Ключевые слова: внутрирегиональная миграция; межрегиональная миграция; международная миграџия; Ростовская область; COVID-19.

\title{
MIGRATION FLOWS OF THE ROSTOV REGION IN THE CONTEXT OF THE COVID-19 PANDEMIC
}

\author{
(C) 2020 Yu. G. Volkov, I. V. Pechkurov, V. G. Panteleev
}

\section{South-Russian branch of the Federal Research Sociological Center of the Russian Academy of Sciences, Rostov-on-Don, Russia}

The aim of the study is to identify the features of the behavior of migration flows in the Rostov region - intraregional, interregional and international-in conditions of restricted movement of people due to the COVID-19 pandemic. In particular, it reveals how much migration flows can recover after the easing of restrictions on movement, that is, their stability.

The methodological basis of the study is, firstly, the observation of changes in statistical series that characterize the dynamics of intraregional, interregional and international migration flows in the Rostov region; secondly, comparative statistics of statistical series in different time periods (annual and monthly), which allows us to identify the relative norm of migration flows and deviations from the norm during the period of restriction of movement of people; third, recording in the observation of changes in statistical series under the influence of a factor and thus determining whether the factor affects the dynamics of the statistical series or not.

Research result. First, it was found that the intraregional migration flow shows a greater sensitivity to the influence of the factor of restricting the movement of people, its volume has decreased; however, it has shown a high degree of reactivation after the easing of restrictions. This did not affect the migration growth of the region due to the peculiarities of intraregional movements. Secondly, it was found that the interregional migration flow is also sensitive to the influence of the factor of restricting the movement of people and at the same time showed a high degree of renewal after the restrictions were eased; also, in the context of the pandemic, a decrease in the intensity of this migration flow reduced the outflow of residents of the Rostov region to other regions. Third, it was found that the international migration flow showed the same properties for those arriving in the region, but these properties did not show up for those leaving the region abroad; the restriction factor had little effect on the decrease in growth due to international migrants. Thus, the migration flows of the Rostov region have experienced a real impact of restrictive measures and at the same time have demonstrated their stability and resiliency after the weakening of the limiting factor.

The research perspective is further scientific observation of changes in migration flows at the regional level and the impact of the factor of limiting the movement of people due to the COVID-19 pandemic. Since the end of the pandemic is poorly predicted, it is likely that restrictive measures will be introduced more than once, so it is important to have the results of observations of the behavior of migration flows in the first period of restrictions, then in the second, third, and so on in order to identify the long-term effect of restrictive measures on the behavior of migration flows at the regional level.

Key words: intraregional migration; interregional migration; international migration; Rostov region; COVID-19. 
Введение. В 2020 году мировое общество столкнулось с неизвестным ранее вирусом, который стал стремительно распространяться по континентам и странам. Угроза массового заражения вирусом, способ лечения которого предстояло найти, поставила руководство стран мира перед выбором: вводить или не вводить меры, ограничивающие контакт людей между собой. «Аргументом» в пользу введения ограничивающих мер помимо всего прочего было и состояние медицинской сферы - во многих странах она была «оптимизирована», и соответствующих специалистов и медицинской техники просто не хватало. Таким образом, основной мерой по предотвращению распространения вируса COVID-19 стало ограничение перемещений людей.

Это ограничение проявилось на нескольких уровнях: от глобального к индивидуальному. Сначала были закрыты границы между странами и прерваны авиасообщения. Затем были введены ограничения перемещений между региональными муниципальными образованиями. Далее - ограничено перемещение между районами регионов. Наконец, многие люди были ограничены в перемещениях собственным жильем и небольшим пространством вокруг него. А те, кому «посчастливилось» стать носителем или заболевшим, вообще были ограничены комнатой в собственном жилье или больничной палатой.

Такое положение вещей неминуемо накладывается на существующие социальные проблемы и грозит различного рода осложнениями. Помимо всплеска доли непрогнозируемой смертности (самое очевидное последствие COVID-19) [5], распространение COVID-19 и меры борьбы с ним поставили в сложное положение экономическую сферу, политическую, социальную [7]. Для социально-демографической группы пожилых людей добавились новые риски и сложности жизни в связи с самоизоляцией [4]. Пандемия особенно остро обнажила проблему социального неравенства, поскольку оказалось, что не все могут себе позволить соблюдать режим самоизоляции [21]. В зоне риска оказалось и такое явление общества, как социальный иммунитет [2], система образования столкнулась с необходимостью осуществлять образовательную деятельность в дистанционном режиме $[10,8]$, также выявились и многие другие вызовы, риски и явления, порожденные глобальной пандемией.

Исследователями приводится множество сценариев развития тех или иных сфер и явлений общественной жизни, которые получат свое продолжение после пандемии COVID-19 [1]. В приведенном перечне отсутствуют миграционные процессы. Хотя исследователями, изучающими миграцию и мигрантов, отмечались проблемы, с которыми мигранты столкнулись в период пандемии [14], тем не менее, очевидно, что после снятия ограничений миграционные потоки, вероятнее всего, возобновят свое движение. Однако существующие обстоятельства благоприятствуют наблюдению за поведением миграционных потоков в условиях действия фактора пандемии COVID-19 и связанных с ней мер противодействия.

В условиях ограничения пространств жизнедеятельности возрастает значение непосредственно данных для человека социально-физических полей деятельности индивидуальных, локальных региональных. Стало быть, является важным прослеживание влияния мер, ограничивающих перемещение людей, связанных с COVID-19, на миграционные потоки в пределах регионального социума. В качестве такого регионального социума в статье рассматривается Ростовская область и ее миграционные потоки: внутрирегиональный, межрегиональный, международный.

Исследования миграции в условиях пандемии COVID-19. Как уже отмечалось, эпидемия и меры по борьбе с ней пронизали многие стороны социальной жизни. Вследствие этого социологи, демографы, экономисты и другие представители дисциплин социального цикла стали свои объекты и предметы исследования рассматривать в ракурсе «ковидной» реальности. С другой стороны, ученые стали рассматривать COVID-19 и сопутствующие ему явления в качестве фактора, влияющего на изучаемую предметную область. В связи с ограничением перемещений людей естественно в таком ракурсе стала рассматриваться миграция и мигранты.

Мировой характер проблемы распространения COVID-19 предрасполагает к тому, чтобы его влияние на миграционные процес- 
сы изучали не только зарубежные ученые, но и отечественные, причем внимание многих отечественных ученых в этом плане простирается далеко за пределы России. В этой группе исследований рассматривались самые различные аспекты. Это перспективы восстановления международных миграционных потоков после эпидемии [18], характер трудовой миграции в условиях пандемии в различных странах [6], влияние условий пандемии на сезонную трудовую миграцию [12], сравнительно-описательные исследования методов регулирования миграционных процессов [13] и др.

Но фактор влияния COVID-19 на миграционные процессы в российском обществе также не остался без внимания ученых. В этом ракурсе рассматривались такие темы, как женская трудовая миграция в России в условиях пандемии [16], положение международных мигрантов на российском рынке труда в условиях распространения COVID-19 [15], риски международных трудовых мигрантов в России в условиях пандемии [11], влияние эпидемии на миграционные процессы и рынок труда в России [11, 17], влияние мер, ограничивающих передвижения людей, на миграционные процессы в отдельных регионах России [3], образ мигрантов в средствах массовой информации в условиях эпидемии [9] и др.

Таким образом, в отечественной научной литературе уже рассматривались различные аспекты влияния условий пандемии COVID-19 на миграционные процессы и на мигрантов как социальную группу. Однако работ, в которых бы прослеживалось влияние периода самоизоляции на миграционные потоки отдельного региона, не наблюдается.

Целью статьи является выявление особенностей миграционных потоков Ростовской области в условиях пандемии COVID-19, а также возможности восстановления миграционных потоков после снятия ограничений. Для этого будут сопоставлены показатели прибывших, выбывших и миграционного прироста за 2019 и 2020 гг. с января по июль (поскольку в статистических источниках приводится количество прибывших и выбывших в 2020 г. по июль). Рассматриваются три потока миграции: внутрирегиональный, межрегиональный, международный. В статье используются данные, размещенные на сайте Единой межведомственной информационностатистической системы ${ }^{1}$.

Внутрирегиональная, межрегиональная и международная миграции Ростовской области и фактор пандемии COVID-19. Меры, ограничивающие передвижение людей в России, действовали в рассматриваемый период с конца марта по конец июня. Статистика позволяет сопоставить количественные данные с этим фактом.

Рассмотрим внутрирегиональную миграцию. Отличительной особенностью этого миграционного потока является то, что он не влияет на численность населения регионального социума, то есть число прибывших людей равняется числу выбывших, но характеризует движение населения между местностями региона (такая статистика по Ростовской области для 2020 г. пока недоступна).

Если сопоставить количество людей, прибывших и выбывших в январе-феврале и июне-июле 2019 и 2020 гг., то окажется, что эти показатели являются сопоставимыми по отношению друг к другу (разница колеблется в пределах чуть более 500 человек) [19, 20]. Следовательно, мы можем рассматривать количество прибывших и выбывших в 2019 г. условно как норму (поскольку не влияет фактор пандемии COVID-19). На рисунке 1 поведение показателя внутрирегионального движения населения Ростовской области можно увидеть более наглядно.

Количество прибывших и выбывших в 2020 г. начинает отклоняться от условной нормы в марте (в конце марта была объявлена «нерабочая неделя») и достигает наибольшего отклонения в апреле и мае. В апреле разница с показателями 2019 г. составила 2862 человека, в мае она составила 1758 человек. В июне-июле разница показателей 2019 и 2020 гг. сокращается и находится в пределах нормы. Следовательно, можно заключить, что меры по самоизоляции возы-

1 Единая межведомственная информационно-статистическая система (ЕМИСС). Режим доступа: https:// www.fedstat.ru. 
мели действие в апреле-мае, и многие люди, перемещающиеся внутри региона, не проигнорировали их. Вместе с тем наличие некоторого числа перемещающихся внутри региона людей может говорить о том, что эти лица заняты на производствах, работу которых прерывать нельзя. С другой стороны, для восстановления прежнего уровня внутрирегиональной миграции не потребовалось много времени - как только ограничения были сняты, она вышла приблизительно на уровень 2019 г. Наконец, с третьей стороны, при отмене ограничительных мер и продолжении пандемии COVID-19 миграционный внутрирегиональный поток ведет себе так же, как в условиях отсутствия пандемии.

В двух других миграционных потоках количество прибывших и выбывших Ростовской области может существенно разниться. Следовательно, эти показатели характеризуют либо миграционный прирост региона, либо его миграционную убыль.

При сопоставлении показателей межрегиональной миграции 2019 и 2020 гг. наблюдается приблизительно такая же картина, как и во внутрирегиональной миграции. Имеет-
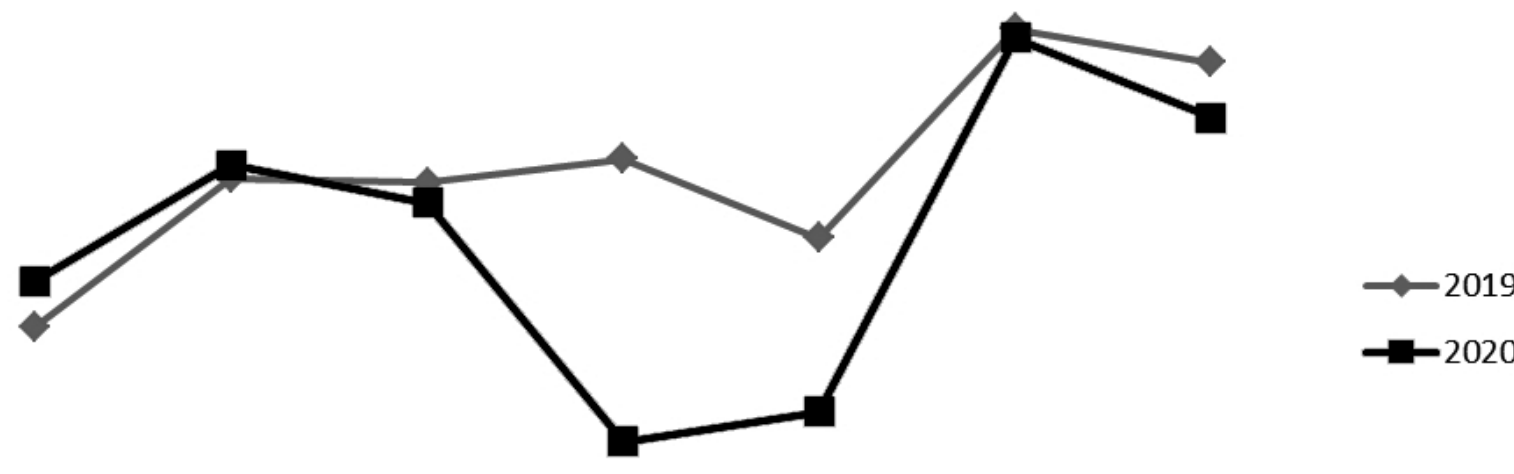

январь февраль март апрель май июнь июль

Рис. 1. Динамика количества прибывших и выбывших внутрирегиональной миграции Ростовской области, 2019 и 2020 гг.
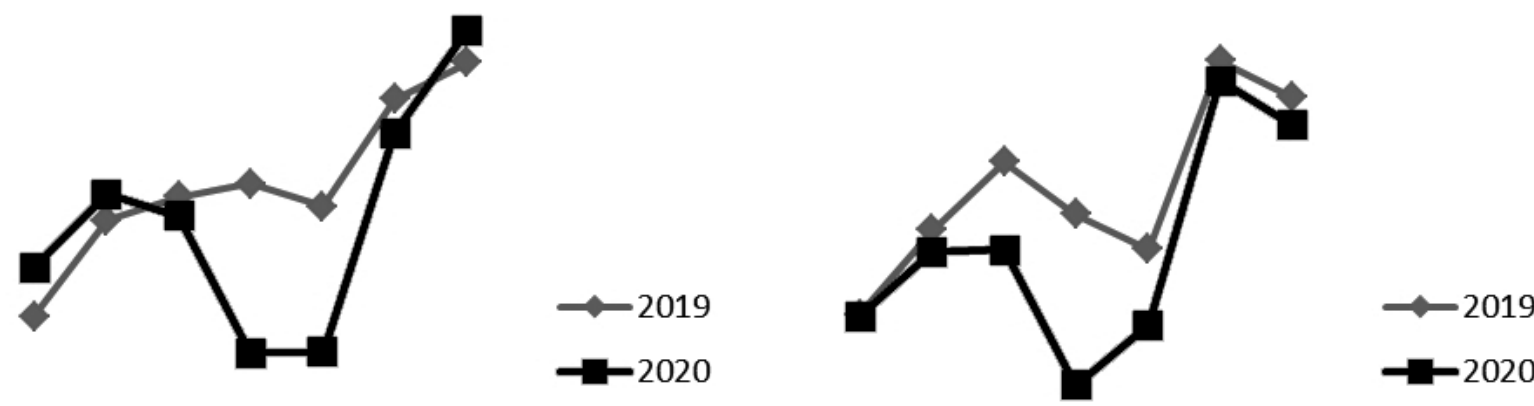

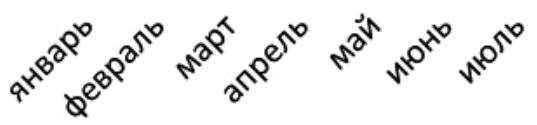

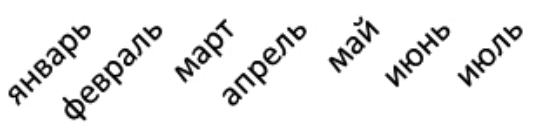

Рис. 2. Динамика количества прибывших (слева) и выбывших (справа) межрегиональной миграции Ростовской области, 2019 и 2020 гг. 
ся незначительная разница в январе-феврале и июне-июле, что по количеству прибывших, что по количеству выбывших из Ростовской области людей (максимальная разница достигает 373 человек) [19, 20]. Стало быть, и в этом изменение количества прибывших и выбывших людей Ростовской области приближено к условной норме 2019 г.

На рисунке 2, отображающем изменение количества людей, прибывших в межрегиональной миграции Ростовской области, видно, что рассматриваемый показатель в 2019 и в 2020 гг. изменяется примерно так же, как в случае с внутрирегиональной миграцией. Количество людей, прибывших в Ростовскую область из других регионов, несколько уменьшается в конце марта, в апреле-мае наблюдается резкое снижение количества прибывших. В апреле разница между 2019 и 2020 гг. составляет 1303 человека, в мае 1122 человека. Очевидно, что это результат действия мер по ограничению перемещений людей и действия средств массовой информации. В июне-июле миграционный поток прибывающих в Ростовскую область из других регионов восстанавливается.

Поведение изменения количества людей, выбывших из Ростовской области, несколько отличается от внутрирегиональной миграции. В 2019 и в 2020 гг. здесь месяцев с незначительной разницей количества выбывших меньше - расхождения наблюдаются уже в марте (рисунок 2, график справа). В апреле
2020 г. наблюдается наименьшее количество выбывших из Ростовской области, в мае численность людей, выбывающих из Ростовской области, начинает восстанавливаться и в июне-июле достигает количества, сопоставимого с количеством 2019 г. Таким образом, реальное уменьшение количества людей, выбывающих из Ростовской области в другие регионы, тоже связано с мерами, ограничивающими перемещения людей из региона и в регион.

Сказались ли ограничительные меры на межрегиональном миграционном приросте или убыли людей в Ростовской области? Сравнение суммарных показателей 2019 и 2020 гг. с января по июль говорит о том, что тенденция межрегиональной убыли населения Ростовской области уменьшилась. В 2019 г. показатель убыли составил -1930 человек, в 2020 г. этот показатель составил -457 человек.

Таким образом, для межрегиональной миграции Ростовской области в период пандемии COVID-19 характерны те же свойства, что и у внутрирегиональной: ограничительные меры реально оказали воздействие на перемещения людей, после ослабления ограничительных мер миграционный поток межрегиональной миграции быстро восстановился и ведет себя так же, как в условиях отсутствия действия фактора пандемии. Вместе с тем ограничительные меры в 2020 г. несколько уменьшили уровень миграции людей из Ростовской области.
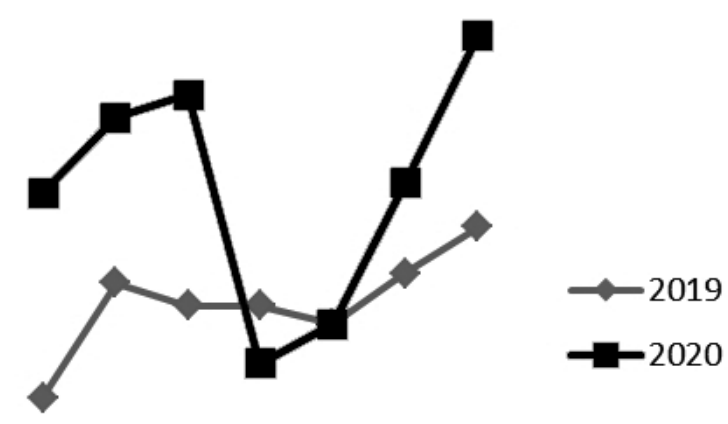
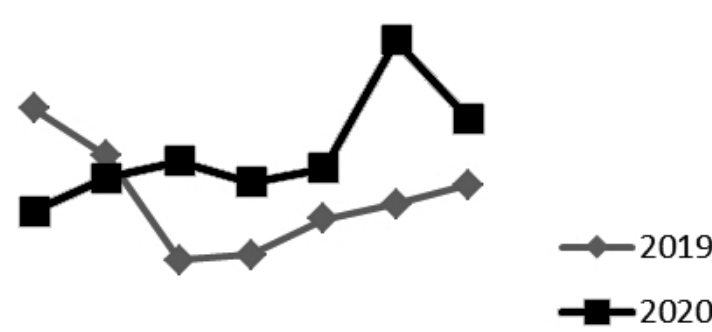

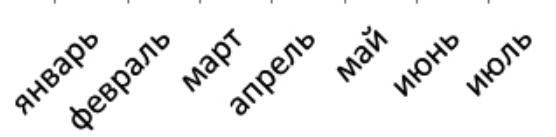

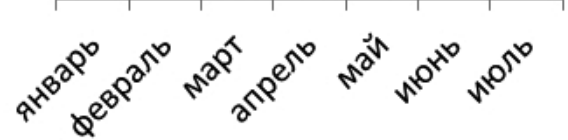

Рис. 3. Динамика количества прибывших (слева) и выбывших (справа) международной миграции Ростовской области, 2019 и 2020 гг. 
Наконец, обратимся к международному потоку миграции Ростовской области. По рисунку 3 заметно, что в потоках международной миграции представляется установить «норму» по 2019 г. лишь по количеству прибывших в Ростовскую область, и то лишь в плане общей тенденции $[19,20]$. Графики, отображающие изменение количества выбывших Ростовской области, и в 2019 г., и в 2020 г. ведут себя отлично друг от друга. Следовательно, в случае с людьми, выбывающими из Ростовской области, необходимо сосредоточится на 2020 г. и месяцах, в которые действовали меры, ограничивающие перемещения людей.

Кривые графиков количества людей, прибывших в Ростовскую область в 2019 и 2020 гг., демонстрируют одну и ту же тенденцию: увеличение количества от месяца к месяцу. Однако количество прибывших в 2020 г. заметно больше, чем в 2019 г. В целом наблюдается такое поведение изменений, как и в рассмотренных ранее миграционных потоках: в апреле и мае 2020 г. наблюдается резкое сокращения притока международных мигрантов в Ростовскую область, в июне миграционный поток начинает движение на прежний уровень и уже в июле выходит на уровень прерванной тенденции.

В 2020 г. количество людей, выбывших из Ростовской области за рубеж, меняется, видимо, под действием других факторов. Так, в месяцы, в которые действуют меры, ограничивающие перемещение людей, не наблюдается резкого уменьшения числа выбывших людей. Отличия между месяцами 2020 г. не резкие, за исключением июня, в котором наблюдается всплеск людей, выезжающих из Ростовской области за рубеж. По-видимому, решимость уехать из России перевешивала эпидемиологическую опасность и риск наказания за нарушение режима. Таким образом, график, отражающий динамику выбытия людей из Ростовской области, является не типичным по сравнению с другими миграционными потоками. Наконец, на прирост людей в Ростовской области за счет мигрантов из других стран ограничительные меры никак не повлияли. Несмотря на резкое уменьшение количества прибывших в апреле-мае 2020 г., в Ростовской области наблюдается прирост, причем он почти в два раза больше чем в 2019 г. (7909 и 4453 человек).

В целом количество людей, прибывших в международном миграционном потоке Ростовской области, меняется так же, как и в миграционных потоках, рассмотренных выше. Нетипично изменение количества выбывших, которое, несмотря на ограничительные меры, менялось слабо.

Заключение. Таким образом, после рассмотрения и сопоставления количественных показателей трех миграционных потоков Ростовской области, можно сделать следующие выводы:

- по изменению количества прибывших во всех трех миграционных потоках наблюдается закономерность: во время действия мер, ограничивающих передвижение людей, приток мигрантов в Ростовскую область резко сокращался (апрель-май), в то же время при ослаблении ограничительных мер миграционные потоки по количеству прибывших быстро выходили на прежний уровень;

- по изменению количества выбывших в зависимости от действия ограничительных мер наблюдаются схожие тенденции во внутрирегиональном и межрегиональном миграционных потоках, т.е. резкое уменьшение количества выбывших в апреле-мае (действие ограничительных мер) и быстрое восстановление уровня выбытия после ослабления ограничительных мер. В то же время количество жителей Ростовской области, выбывших за рубеж, не сильно менялось под воздействием ограничительных мер;

- ограничительные меры оказали влияние на межрегиональный миграционный поток: миграционная убыль Ростовской области оказалась в 2020 г. значительно ниже, чем в 2019 г. В то же время ограничительные меры не оказали влияния на миграционный прирост за счет международного миграционного потока: он оказался значительно выше в 2020 г., нежели в 2019 г;;

- в целом на краткосрочном периоде ограничения перемещений людей все три миграционных потока Ростовской области демонстрируют устойчивость и быстро восстанавливаются.

Таким образом, миграционные потоки Ростовской области оказались чувствительны 
к ограничениям, которые направлены на борьбу с распространением COVID-19, и в то же время они устойчивы и возобновляемы.

\section{Литература}

1. Волков Ю.Г., Курбатов В.И. Глобальная социология пандемии: отечественные и зарубежные сценарии и тренды послекоронавирусного мира // Гуманитарий Юга России. - 2020. - Т. 9. - №2. - С. 17-32.

2. Гафиатулина Н.Х., Касьянов В.В., Самыгин С.И. Социальный иммунитет российского общества в условиях угрозы коронавируса: риски социокультурной травматизации// Гуманитарий Юга России. - 2020. T. 9. 一 №2. - С. 147-158.

3. Джсиоев A.В. Самоизоляция в России как фактор миграции населения Северо-Кавказского федерального округа // Вестник Северо-Осетинского государственного университета имени К. Л. Хетагурова. — 2020. №3. - С. 146-156.

4. Доброхлеб В. Г. Современная пандемия и риск роста социальной изоляции пожилых людей // Научное обозрение. Серия 1: Экономика и право. - 2020. - №3. - С. 166-173.

5. Иванов С. Ф. Смертность от COVID-19 на фоне других всплесков смертности XX века // Демографическое обозрение. 2020. — Т. 7. — №2. - С. 143-151.

6. Имидеева И.В., Болдбаатар Н., Медведь B.A. Трудовая миграция в Монголии в период пандемии COVID-19 // Научное обозрение. Серия 1: Экономика и право. 2020. - №3. - C. 122-133.

7. Курюкин А. Н. COVID-19 как вызов экономике, социуму, политике // МИР (Модернизация. Инновации. Развитие). - 2020. T. 11. - №3. - C. 250-265.

8. Леонидова Г.В., Валиахметов Р.М., Баймурзина Г.Р., Бабич Л.В. Проблемы и перспективы дистанционного обучения в оценках учителей и родителей обучающихся // Экономические и социальные перемены: факты, тенденции, прогноз. - 2020. T.3. - №4. - C. 202-219.

9. Леденева В. Ю., Безвербная Н. А. Формирование образа мигранта в СМИ и социальных сетях на фоне эпидемии COVID-19 (по результатам контент-анализа интернетизданий) // Научное обозрение. Серия 1:
Экономика и право. - 2020. - №3. C. $95-105$.

10. Лубский А. В., Ковалев В. В. От «онлайнизации» высшей школы к онлайнобразованию // Гуманитарий Юга России. 2020. - T. 9. - №2. - С. 33-50.

11. Потапова А. А. Риск ограничения занятости иностранных мигрантов в сельском хозяйстве России в условиях пандемии // Экономическое развитие России. - 2020. T. 27. - №6. - C. 44-53.

12. Потемкина О.Ю. Европейский союз: сезонные рабочие в условиях пандемии // Научно-аналитический вестник Института Европы РАН. - 2020. - №5 (17). - С. 45-51.

13. Прыткова А. О. Коронавирус: сравнение мирового опыта в сфере ограничения миграции // Развитие политических институтов и процессов: зарубежный и отечественный опыт. Сборник научных статей XI Всероссийской научно-практической конференции с международным участием. Редколлегия: Н.В. Кефнер, Ю.В. Попова (отв. ред.) [и др.]. - 2020. - С. 640-645.

14. Рязанцев С.В., Брагин А.Д., Рязанuев Н.C. Положение трудовых мигрантов в регионах мира: вызовы пандемии COVID-19 и реакция правительств // Научное обозрение. Серия 1: Экономика и право. 2020. - №3. - С. 7-21.

15. Рязаниев С.В., Письменная Е.Е., Перемышилин С.Н. Положение трудовых мигрантов из стран Центральной Азии на российском рынке труда // Вопросы национальных и федеративных отношений. - 2020. T. 10. — №5 (62). - C. 1248-1259.

16. Сивоплясова С.Ю. Женская трудовая миграция в период пандемии COVID-19// Научное обозрение. Серия 1: Экономика и право. - 2020. - №3. - С. 106-113.

17. Титова A.В. Влияние пандемии и условия ЧС (приближенной к ЧС) на миграционные процессы и баланс трудовых ресурсов в Российской Федерации // Постсоветские исследования. - 2020. - Т. 3. - №4. - С. 342-348.

18. Храмова М.Н., Зорин Д. П., Туан Б.К., Морозов В. М. Влияние пандемии COVID-19 на мобильность населения Вьетнама и Таиланда и перспективы восстановления международной миграции // Научное обозрение. Серия 1: Экономика и право. - 2020. №3. - С. 34-44. 
19. Число выбывших [Электронный pecypc] // Единая межведомственная информационно-статистическая система (ЕМИСС). - Режим доступа: https://www. fedstat.ru/indicator/43513.

20. Число прибывших [Электронный pecypc] // Единая межведомственная информационно-статистическая система (ЕМИСС). - Режим доступа: https://www. fedstat.ru/indicator/43514.

21. Шеремет А.Н. Пандемия неравенства. Социально-экономические аспекты и последствия COVID-19 // Медицина. Социология. Философия. Прикладные исследования. - 2020. — №4. - С. 136-141.

\section{References}

1. Volkov Ju. G., Kurbatov V.I. Global'naja sociologija pandemii: otechestvennye i zarubezhnye scenarii i trendy poslekoronavirusnogo mira [Global sociology pandemic: national and international scenarios and trends poslegarantiynoe the world] // Gumanitarij Juga Rossii [Humanities of the South of Russia]. — 2020. Vol. 9. - №2. - Pp. 17-32.

2. Gafiatulina N.H., Kas'janov V. V., Samygin S. I. Social'nyj immunitet rossijskogo obshhestva $\mathrm{v}$ uslovijah ugrozy koronavirusa: riski sociokul'turnoj travmatizacii [The Social immunity of the Russian society in terms of the threat of coronavirus: the risks of social and cultural trauma] // Gumanitarij Juga Rossii [Humanities of the South of Russia]. - 2020. — Vol. 9. №2. - Pp. 147-158.

3. Dzhioev A. V. Samoizoljacija v Rossii kak faktor migracii naselenija Severo-Kavkazskogo federal'nogo okruga [Self-Isolation in Russia as a factor of migration of the population of the North Caucasus Federal district] // Vestnik Severo-Osetinskogo gosudarstvennogo universiteta imeni K. L. Hetagurova [Bulletin of the North Ossetian state University named after K. L. Khetagurov]. - 2020. - №3. Pp. 146-156.

4. Dobrohleb V.G. Sovremennaja pandemija i risk rosta social'noj izoljacii pozhilyh ljudej [Modern pandemic and the risk of growing social isolation of elderly people] // Nauchnoe obozrenie. Serija 1: Jekonomika i pravo [Scientific review. Series 1: Economics and law]. 2020. — №3. - Pp. 166-173.
5. Ivanov S.F. Smertnost' ot COVID-19 na fone drugih vspleskov smertnosti XX veka [Mortality from COVID-19 against the background of other bursts of mortality of the XX century] // Demograficheskoe obozrenie [Demographic review]. - 2020. - Vol. 7. — №2. Pp. 143-151.

6. Imideeva I.V., Boldbaatar N., Medved' V.A. Trudovaja migracija $\mathrm{v}$ Mongolii $\mathrm{v}$ period pandemii COVID-19 [Labor migration in Mongolia during the COVID-19 pandemic] // Nauchnoe obozrenie. Serija 1: Jekonomika i pravo [Scientific review. Series 1: Economics and law]. - 2020. - №3. - Pp. 122-133.

7. Kurjukin A.N. COVID-19 kak vyzov jekonomike, sociumu, politike [COVID-19 as a challenge to the economy, society, and politics] // MIR (Modernizacija. Innovacii. Razvitie) [MID (Modernization. Innovations. Development)]. 2020. - Vol. 11. — №3. - Pp. 250-265.

8. Leonidova G.V., Valiahmetov R.M., Bajmurzina G.R., Babich L.V. Problemy i perspektivy distancionnogo obuchenija $\mathrm{v}$ ocenkah uchitelej i roditelej obuchajushhihsja [Problems and prospects of distance learning in the assessments of teachers and parents of students]// Jekonomicheskie i social'nye peremeny: fakty, tendencii, prognoz [Economic and social changes: facts, trends, forecast]. — 2020. — Vol. 13. №4. - Pp. 202-219.

9. Ledeneva V.Ju., Bezverbnaja N.A. Formirovanie obraza migranta $\mathrm{V}$ SMI i social'nyh setjah na fone jepidemii COVID-19 (po rezul'tatam kontent-analiza internet izdanij) [Formation of the image of a migrant in the media and social networks against the background of the COVID-19 epidemic (based on the results of content analysis of Internet publications)] // Nauchnoe obozrenie. Serija 1: Jekonomika i pravo [Scientific review. Series 1: Economics and law]. 2020. 一 №3. - Pp. 95-105.

10. Lubskij A.V., Kovalev V.V. Ot «onlajnizacii»» vysshej shkoly $\mathrm{k}$ onlajnobrazovaniju [From «onlinesale» high school to onlineberatung] // Gumanitarij Juga Rossii [Humanities of the South of Russia]. - 2020. — Vol. 9. №2. - Pp. 33-50.

11. Potapova A.A. Risk ogranichenija zanjatosti inostrannyh migrantov $\mathrm{v}$ sel'skom hozjajstve Rossii v uslovijah pandemii [Risk of limiting the employment of foreign migrants in agriculture of Russia in conditions of a pandemic]// 
Jekonomicheskoe razvitie Rossii [Economic development of Russia]. — 2020. - Vol. 27. №6. - Pp. 44-53.

12. Potemkina O. Ju. Evropejskij sojuz: sezonnye rabochie $\mathrm{v}$ uslovijah pandemii [European Union: seasonal workers in a pandemic] // Nauchno-analiticheskij vestnik Instituta Evropy RAN [Scientific and analytical Bulletin of the Institute of Europe of the Russian Academy of Sciences]. - 2020. — №5 (17). — Pp. 45-51.

13. Prytkova A.O. Koronavirus: sravnenie mirovogo opyta $\mathrm{v}$ sfere ogranichenija migracii [Coronavirus: comparison of world experience in the field of migration restriction] // Razvitie politicheskih institutov i processov: zarubezhnyj i otechestvennyj opyt. Sbornik nauchnyh statej XI Vserossijskoj nauchno-prakticheskoj konferencii s mezhdunarodnym uchastiem [Development of political institutions and processes: foreign and domestic experience. Collection of scientific articles of the XI all-Russian scientific and practical conference with international participation]. In N.V. Kefner, Ju. V. Popova (eds.). - 2020. - Pp. 640-645.

14. Rjazancev S.V., Bragin A.D., Rjazancev N.S. Polozhenie trudovyh migrantov $\mathrm{v}$ regionah mira: vyzovy pandemii COVID-19 i reakcija pravitel'stv [The situation of labor migrants in the world's regions: challenges of the COVID-19 pandemic and government response] // Nauchnoe obozrenie. Serija 1: Jekonomika i pravo [Scientific review. Series 1: Economics and law]. - 2020. — №3. - Pp. 7-21.

15. Rjazancev S. V., Pis'mennaja E. E., Peremyshlin S. N. Polozhenie trudovyh migrantov iz stran Central'noj Azii na rossijskom rynke truda [The situation of labor migrants from Central Asian countries on the Russian labor market] // Voprosy nacional'nyh i federativnyh otnoshenij [Questions of national and Federal relations]. 2020. — Vol. 10. — №5 (62). — Pp. 1248-1259.

16. Sivopljasova $S$. Ju. Zhenskaja trudovaja migracija v period pandemii COVID-19 [Women's labour migration in the period of the pan- demic COVID-19] // Nauchnoe obozrenie. Serija 1: Jekonomika i pravo [Scientific review. Series 1: Economics and law]. — 2020. — №3. Pp. 106-113.

17. Titova $A$. $V$. Vlijanie pandemii i uslovija $\mathrm{ChS}$ (priblizhennoj $\mathrm{k} \mathrm{ChS}$ ) na migracionnye processy i balans trudovyh resursov v Rossijskoj Federacii [The impact of the pandemic and the conditions of an emergency (close to an emergency) on migration processes and the balance of labor resources in the Russian Federation]// Postsovetskie issledovanija [Post-Soviet research]. 2020. — Vol. 3. — №4. - Pp. 342-348.

18. Hramova M.N., Zorin D.P., Tuan B.K., Morozov V.M. Vlijanie pandemii COVID-19 na mobil'nost' naselenija V'etnama i Tailanda i perspektivy vosstanovlenija mezhdunarodnoj migracii [Impact of the COVID-19 pandemic on the mobility of the population of Vietnam and Thailand and prospects for restoring international migration] // Nauchnoe obozrenie. Serija 1: Jekonomika i pravo [Scientific review. Series 1: Economics and law]. — 2020. — №3. Pp. 34-44.

19. Chislo vybyvshih [Number of retired] [Jelektronnyj resurs] // Edinaja mezhvedomstvennaja informacionno-statisticheskaja sistema (EMISS) [Unified interagency information and statistical system (UIISS)]. — URL: https:// www.fedstat.ru/indicator/43513.

20. Chislo pribyvshih [Number of arrivals] [Jelektronnyj resurs] // Edinaja mezhvedomstvennaja informacionno-statisticheskaja sistema (UIISS). — URL: https://www.fedstat.ru/indicator/43514.

21. Sheremet A.N. Pandemija neravenstva. Social'no-jekonomicheskie aspekty i posledstvija COVID-19 [Pandemic of inequality. Socio-economic aspects and consequences of COVID-19] // Medicina. Sociologija. Filosofija. Prikladnye issledovanija [Medicine. Sociology. Philosophy. Applied research]. — 2020. №4. - Pp. 136-141. 


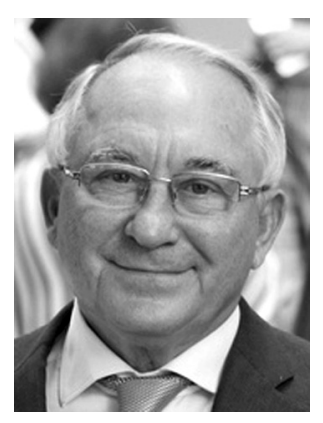

Волков Юрий Григорьевич - Заслуженный деятель науки РФ, доктор философских наук, профессор, научный руководитель Института социологии и регионоведения Южного федеральногно университета, заведующий кафедрой теоретической социологии и методологии региональных исследований ИСиР ЮФУ. Руководитель, главный научный сотрудник ЮжноРоссийского филиала Федерального научно-исследовательского социологического центра Российской академии наук (ЮРФ ФНИСЦ РАН). Действительный член Российской академии социальных наук, действительный член Нью-Йоркской академии наук (1995). Специалист в области исследований социологии креативности и креативного класса в российской социологической науке, социальной имитации, гуманистической идеологии, формирования идентичности. Основатель и руководитель научной школы «Многоуровневая идентичность и идеология инновационного развития российского общества». Лауреат премии им. И.Г. Петровского, награжден серебряной медалью им. П. Сорокина за вклад в развитие социологии в России, серебряной медалью им. П. Сорокина за вклад в науку, серебряной медалью «Джим Торосян». Общий стаж научно-педагогической работы составляет более 50 лет.

Volkov Yury Grigiryevich - Honored scientist of the Russian Federation, Doctor of Philological Sciences, Professor, Scientific Director of the Institute of Sociology and Regional Studies of the Southern Federal University, Head of the Department of Theoretical Sociology and Methodology of Regional Studies of the Institute of Sociology and Regional Studies of the Southern Federal University. Director, Chief researcher of the South Russian Branch of Science of the Federal Center of Theoretical and Applied Sociology of the Russian Academy of Sciences. Member of the Russian Academy of Social Sciences, Member of the New York Academy of Sciences (1995). Specialist in the field of research on the sociology of creativity and the creative class in Russian sociological science, social imitation, humanistic ideology, identity formation. Founder and head of the scientific school «Multilevel identity and ideology of innovative development of Russian society». I. G. Petrovsky prizewinner, was awarded P. Sorokin silver medal for his contribution to the development of sociology in Russia, P. Sorokin silver medal for his contribution to science, «Jim Torosyan» silver medal. The general experience of scientific and pedagogical work is more than 50 years.

344006, г. Ростов-на-Дону, ул. Пушкинская, 160 160 Pushkinskaya st., 344006, Rostov-on-Don, Russia E-mail: ugvolkov@sfedu.ru 


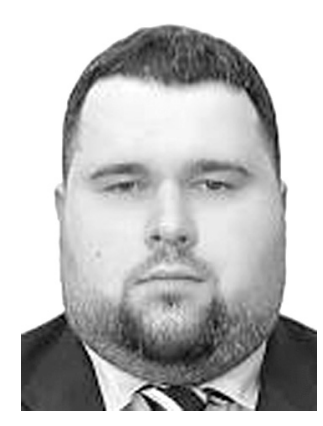

Печкуров Илья Васильевич - кандидат социологических наук, старший научный сотрудник Южно-Российского филиала Федерального научно-исследовательского социологического центра Российской академии наук (ЮРФ ФНИСЦ РАН). Специалист в области исследований демонстративного потребления, миграционных процессов, формирования государственно-гражданской идентичности. Стаж научной работы 4 года.

Pechkurov Ilya Vasylevich - Candidate of Sociological Sciences, Senior Researcher of the South Russian branch of the Federal Center of Theoretical and Applied Sociology of the Russian Academy of Sciences. Specialist in the field of research on demonstrative consumption, migration processes, and the formation of state and civil identity. 4 years of research experience.

344006, г. Ростов-на-Дону, ул. Пушкинская, 160 160 Pushkinskaya st., 344006, Rostov-on-Don, Russia E-mail: i.pechkurov@gmail.com

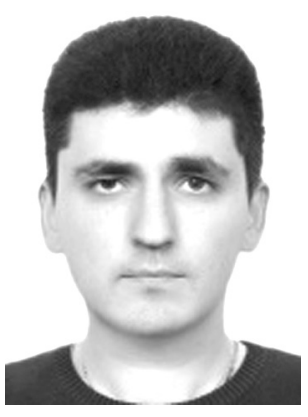

Пантелеев Вадим Геннадьевич - социолог, младший научный сотрудник Южно-Российского филиала Федерального научно-исследовательского социологического центра Российской академии наук (ЮРФ ФНИСЦ РАН). Сфера научных интересов: социальная субъектность, социальные отношения и процессы. Стаж работы в научно-исследовательской сфере - 3 года.

Panteleev Vadim Gennadyevich - Sociologist, Junior Researcher of the South Russian branch of the Federal Center of Theoretical and Applied Sociology of the Russian Academy of Sciences. Research interests: social agency, social relations and processes. Work experience in the research field is 3 years.

344002, г. Ростов-на-Дону, ул. Максима Горького, 102 102 Maxim Gorky st., 344002, Rostov-on-Don, Russia E-mail:pwg92@mail.ru 